\title{
OPTIMISATION OF MODELS FOR THE DETERMINATION OF THE CREST OF BARS ON SANDY BEACHES
}

\author{
ISABEL LÓPEZ ${ }^{1}$, YOLANDA VILLACAMPA ${ }^{2}$, JOSE IGNACIO PAGÁN ${ }^{1}$, \\ FRANCISCO JOSÉ NAVARRO-GONZÁLEZ ${ }^{2} \&$ LUIS ARAGONÉS ${ }^{1}$ \\ ${ }^{1}$ Department of Civil Engineering, University of Alicante, Spain \\ ${ }^{2}$ Department of Applied Mathematics, University of Alicante, Spain
}

\begin{abstract}
Sand bars are important morphological characteristics of beaches, and changes in their position and height are the main causes of profile variability. The cross-shore movement of the bars can be important for the artificial beach nourishments, because the success of the latter depends on its interaction with the bar position. Therefore, it is important to determine the location of the bars in the profile. The aim of this work is to evaluate the different existing models, and to obtain an optimized model that uses the least possible number of variables and obtains the best results. First of all, a total of 25 variables related to the characteristics of the waves, sediment and physical characteristics of the beach have been studied by means of a correlation analysis. Secondly, we have tried to generate linear models using the backward method, which generates successive models eliminating variables in each of them. These models, however, did not offer good results, with R2 values lower than 0.4. For this reason, different numerical models have been generated using among others the same variables used by different authors in their formulations or models. The numerical models of finite elements use Galerkin's methodology and show that the most influential variables on the location of the bars crest are: wave height, period and median sediment size. These variables are very similar to those proposed by other authors; however, the formulations proposed by these authors do not offer good results in the area of study, while with the models generated, the errors committed in absolute value are less than $8 \%$. This leads us to the final idea that the influential variables in the bars are the same in any study area, but the degree of influence or relationship with the study parameter depends on the study area.
\end{abstract}

Keywords: bar crest, sand beaches, numerical models, Galerkin's methodology.

\section{INTRODUCTION}

Sand bars are an important morphological feature of natural beaches. In many places, changes in the position and height of the bar are the main causes of profile variation [1]. The bars also significantly affect the transformation of the wave and therefore the subsequent evolution of the profile [2], [3]. However, the formation and evolution of the sandbanks are little known. Holman and Sallenger [1] reviewed the hypotheses for sand bar formation and concluded that both the breaking point [4] and the infragravity wave [5] may be important.

Several researchers have suggested mechanisms that could cause bars to migrate to the coast. Trowbridge and Young [6] demonstrated that, under moderately energetic waves, the flow generated by the amount of movement in the boundary layer has a local maximum on the bar. They suggested that this would lead to a maximum in the transport of sediments towards the coast over the bar, and to the migration of the bars towards the coast. The Trowbridge and Young [6] model successfully predicted a bar-to-shore migration event observed on a natural beach, but this model excludes sediment transport by hangover and fails to predict inshore migration.

Among the different models developed for bar prediction, the most commonly used variables are wave height in deep water $\left(\mathrm{H}_{\mathrm{o}}\right)$, period $(\mathrm{T})$ or wavelength in deep water $\left(\mathrm{L}_{\mathrm{o}}\right)$, and median sediment size expressed explicitly $\left(\mathrm{D}_{50}\right)$ or implicitly (fall velocity; $\mathrm{w}=14 \cdot \mathrm{D}_{50}{ }^{1.1}$ ) 
[7]-[11]. Some of these authors also incorporate in their models the wave height at break $\left(\mathrm{H}_{\mathrm{b}}\right)$ [8], [9], [11] and/or the slope $(\mathrm{m})$ [8], [10]. It is worth noting the maximum wave height $\left(\mathrm{H}_{\max }\right)$ used by Plant et al. [8], the wave incidence direction with respect to the beach normal $(\theta)$ used by Pape et al. [9], and the tidal range integrated by Masselink and Short [11]. In addition, most of these models also take into account the wave duration time $(\mathrm{t})$.

Therefore, the aim of this work is to optimize the current models. For this purpose, a numerical model will be determined, which provides the position of the bar crest as precisely as possible and uses as few variables as possible. In addition, the most influential variables in the position of the bar crest will be determined, for which different models will be generated using some of the variables proposed by other authors and other new variables.

\section{STUDY AREA}

The area under study covers a length of $17.7 \mathrm{~km}$ of the Valencia coast (Spain) (Fig. 1). The area is divided into two distinct morphodynamic units to the North and South of the Port of Valencia. The beaches in these areas are of fine sand, with median sediment sizes between $0.172 \mathrm{~mm}$ and $0.452 \mathrm{~mm}$. It is a micromareal zone, with astronomical tides ranging between 20 and $30 \mathrm{~cm}$, and together with meteorological tides can reach up to $75 \mathrm{~cm} \mathrm{[12].}$

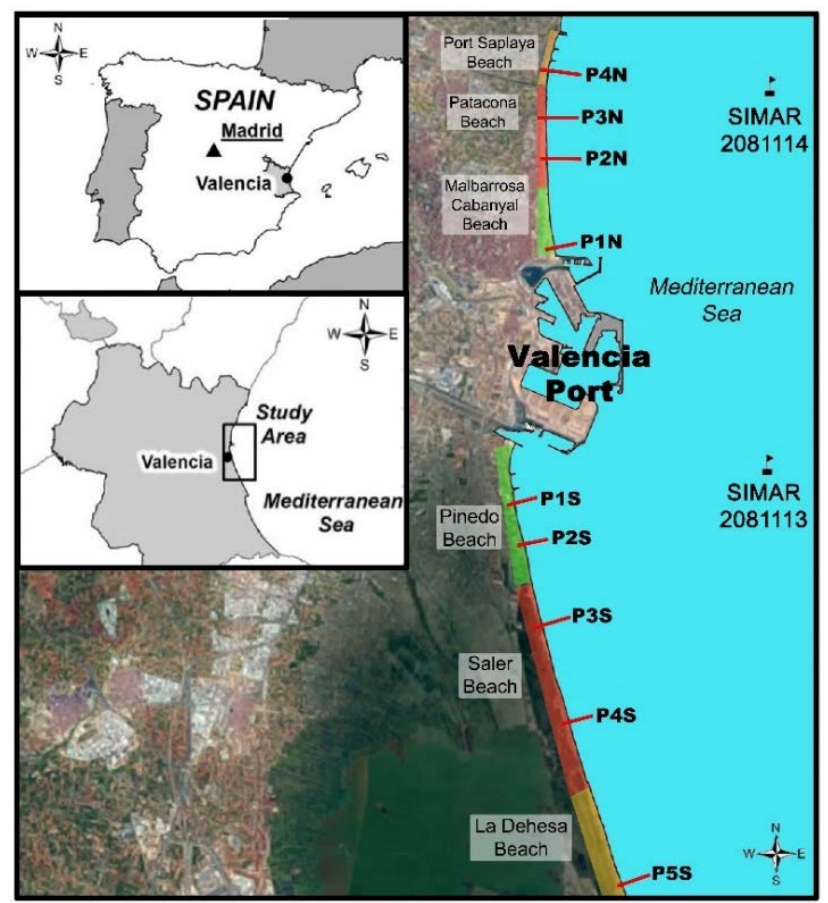

Figure 1: Location of the study area and the analysed profiles.

In Fig. 1, the nine representative points where the profiles of this study have been taken are observed (four profiles to the North of the Port and five to the South). In the northern area are the profiles P1N (Malbarrosa-Cabanyal Beach), P2N and P3N (Patacona Beach) and P4N (Port Saplaya Beach). In the southern zone that occupies about $13 \mathrm{~km}$ are the profiles P1S and P2S (Pinedo Beach), P3S and P4S (Saler Beach) and P5S (La Dehesa Beach). 


\section{METHODOLOGY}

Below is a description of the procedure followed to obtain the data necessary for the study, as well as the procedure followed in the generation of the different numerical models.

\subsection{Data collection}

The methodology followed for the determination of the position of the bars crest and obtaining the different characteristics of the waves and sedimentology is presented.

\subsubsection{Position of the bar crest}

In order to determine the position of the bars, 209 precision profiles (error less than $2 \mathrm{~cm}$ ) were obtained using the Profiling Bar method (BP) [13]. This method has a system of joinable bars with an articulated foot and a crown with two reflective prisms that make it possible to determine the height of the beach profile, independently of the mean sea level.

The frequency of profiling was not regular. In the period 1992-1994, the profiles were taken every 2 months, from 1994-1997 every 4 months and during the period 2005-2014 they were taken every 6 months, in April and October of each year.

Each of the profiles was carefully analysed and the distance to the coastline and the depth of the bar crest was obtained for each of them.

\subsubsection{Maritime climate}

Wave data were obtained from SIMAR (time series of wind and wave parameters from numerical modelling) node data (recorded every 3 hours since 1958) provided by the Puertos del Estado Public Agency. Specifically, the data of the nodes SIMAR 2081114 (North zone with 62489 wave height data since 1992) and SIMAR 2081113 (South zone with 62489 wave height data since 1992) were used.

For the study of the waves in each of the profiles studied, a sectorization of the incoming energy was carried out first, discarding those waves that do not affect the profile. Next, for each of the profiles and the period elapsed between the taking of each profile, Carol v1.0 [14] was used to obtain the wave height $\mathrm{H}_{\mathrm{s}, 12}$ (wave height exceeded only 12 hours per year, with a probability of $0.137 \%$ regardless of the period studied) and the maximum wave height $\left(\mathrm{H}_{\max }\right)$ produced in each period studied, as well as their corresponding periods $(\mathrm{T})$ and directions $(\theta)$.

\subsubsection{Sedimentology}

Finally, the median sediment size ( $\mathrm{D}_{50}$ ) (UNE-EN 933-1:2012) corresponding to each of the studied profiles in the dry beach was obtained. For this purpose, the samples corresponding to these profiles collected during the sampling campaign carried out by the University of Alicante in 2013 were used.

\subsection{Model generation}

Initially, linear models were studied considering all the variables, for which the backward method was applied, starting with a linear model of 24 explanatory variables to eliminate one by one the variables. All models had a bad fit with a maximum value of $\mathrm{R}^{2}$ of 0.4 . This indicates that there are no linear relationships between the considered explanatory variables and the bars crest position. Therefore, it is necessary to analyse non-linear relationships.

Before generating the numerical models, a correlation study was carried out to see the influence of each of the variables. Given that the values of $r$ obtained in the study of correlations between the different variables and the position ( $\mathrm{x}$ and $\mathrm{y}$ ) of the bar crest were 
very weak $(0.0-0.2)$, it was decided to generate models using the variables most used by other authors and gradually adding variables. Six models were generated with the following input variables:

1. M1: Hs, 12 and T

2. M2: Hs, 12 and $\mathrm{m}$

3. M3: Hs, 12 and D50

4. M4: Hs, 12, $\mathrm{T}$ and $\mathrm{m}$

5. M5: Hs, 12, T and D50

6. M6: Hmax, Hs, 12, T and $\mathrm{m}$

The numerical models were generated according to the methodology developed in Navarro-González and Villacampa [15]. This methodology is based on Galerkin's formulation [16], [17] of the finite element method and improves the computational efficiency of the algorithms of the numerical methodologies used by the authors in other research [15], [18]-[21]. A model is generated for each finite element or mesh model defined in a hyper cube. As usual, each finite element mesh is determined by its complexity (mesh density) which is defined as the number of elements defined along each edge of the hypercube. Therefore, for each data set (M1, M2, M3, M4, M5 and M6) families of models were generated from the selected complexity.

To evaluate the performance of each model, the results obtained were compared with the formulations proposed by Hsu [22], Silvester and Hsu [23], Günaydın and Kabdaşlı [24] and Kömürcü et al. [25], as well as the artificial neural network (ANN) proposed byLópez et al. [26]. The results were compared in terms of $\mathrm{R}^{2}$, absolute error (eqn 1) and mean absolute percentage error (MAPE) (eqn (2))

$$
\begin{gathered}
\varepsilon=\sqrt{\frac{\sum_{\mathrm{i}=1}^{\mathrm{N}}\left(\mathrm{a}^{\mathrm{i}}-\mathrm{d}^{\mathrm{i}}\right)^{2}}{\mathrm{~N}-\mathrm{p}},} \\
\text { MAPE }=\frac{1}{\mathrm{~N}} \sum_{\mathrm{i}=1}^{\mathrm{N}}\left|\frac{\mathrm{a}^{\mathrm{i}}-\mathrm{d}^{\mathrm{i}}}{\mathrm{a}^{\mathrm{i}}}\right| .
\end{gathered}
$$

\section{RESULTS}

First, the results for $\mathrm{R}^{2}$ obtained for each of the models generated are shown (Table 1). As can be seen, the models with two variables (M1, M2 and M3) yield $R^{2}$ values lower than 0.8 for both $\mathrm{x}$ and $\mathrm{y}$ (distance to shore and depth of bar crest) in almost all complexities. While the other three models reach values higher than 0.8 with relatively low complexities, the M5 model reaches values higher than 0.9 from complexity 60 . In addition, as complexity increases, the value of $\mathrm{R}^{2}$ increases until it reaches values of 0.96 for complexity of 100 in $\mathrm{x}$ and 0.96 for complexity of 130 .

On the other hand, if the absolute error (Table 2) and the MAPE (Table 3) are analysed, it can be seen that the errors are relatively small. If the 3-variable models (M4 and M5) are analysed, it can be seen how, for distance from the coast, errors are less than $20 \mathrm{~m}$ for complexity 40, and even less than $10 \mathrm{~m}$ for complexity 70 in the M5 model, which means an MAPE of $10.7 \%$. In the case of depth (y), the M4 model is not capable of lowering the $19 \mathrm{~cm}$ error while the M5 model goes down to $10 \mathrm{~cm}$, which means an MAPE of $8.4 \%$ and $5.4 \%$, respectively. This indicates that the influence of the sediment is greater than that of the slope, given that the results of the M5 model are better than those achieved with the M4, using much lower complexities. As for the results obtained by the M6 model with 4 variables, it can be 
Table 1: $\mathrm{R}^{2}$ values for each of the generated models.

\begin{tabular}{|l|c|c|c|c|c|c|c|c|c|c|c|c|}
\hline \multirow{2}{*}{ Comp. } & \multicolumn{9}{|c|}{ Results for X } & \multicolumn{6}{c|}{ Results for Y } \\
\cline { 2 - 15 } & M1 & M2 & M3 & M4 & M5 & M6 & M1 & M2 & M3 & M4 & M5 & M6 \\
\hline $\mathbf{3 0}$ & 0.188 & 0.503 & 0.400 & 0.636 & 0.691 & 0.666 & 0.192 & 0.353 & 0.405 & 0.560 & 0.678 & 0.603 \\
\hline $\mathbf{4 0}$ & 0.234 & 0.559 & 0.475 & 0.708 & 0.796 & 0.741 & 0.237 & 0.420 & 0.493 & 0.645 & 0.796 & 0.683 \\
\hline $\mathbf{5 0}$ & 0.260 & 0.608 & 0.541 & 0.756 & 0.866 & 0.789 & 0.259 & 0.481 & 0.569 & 0.698 & 0.867 & 0.730 \\
\hline $\mathbf{6 0}$ & 0.278 & 0.650 & 0.587 & 0.796 & 0.905 & 0.826 & 0.274 & 0.532 & 0.624 & 0.739 & 0.906 & 0.764 \\
\hline $\mathbf{7 0}$ & 0.290 & 0.686 & 0.625 & 0.821 & 0.926 & 0.857 & 0.286 & 0.579 & 0.665 & 0.767 & 0.925 & 0.793 \\
\hline $\mathbf{8 0}$ & 0.297 & 0.717 & 0.652 & 0.843 & 0.940 & 0.875 & 0.293 & 0.619 & 0.693 & 0.790 & 0.937 & 0.810 \\
\hline $\mathbf{9 0}$ & 0.304 & 0.744 & 0.674 & 0.860 & 0.951 & 0.890 & 0.299 & 0.654 & 0.714 & 0.808 & 0.945 & 0.826 \\
\hline $\mathbf{1 0 0}$ & 0.309 & 0.765 & 0.688 & 0.872 & 0.957 & 0.902 & 0.303 & 0.682 & 0.727 & 0.821 & 0.950 & 0.839 \\
\hline $\mathbf{1 1 0}$ & 0.313 & 0.786 & 0.702 & 0.886 & & 0.914 & 0.307 & 0.712 & 0.740 & 0.836 & 0.954 & 0.852 \\
\hline $\mathbf{1 2 0}$ & 0.316 & 0.802 & 0.713 & 0.894 & & & 0.309 & 0.734 & 0.751 & 0.846 & 0.957 & 0.861 \\
\hline $\mathbf{1 3 0}$ & 0.319 & 0.815 & 0.719 & 0.903 & & & 0.311 & 0.754 & 0.756 & 0.857 & 0.960 & \\
\hline
\end{tabular}

Table 2: Absolute error values for each of the generated models.

\begin{tabular}{|l|c|c|c|c|c|c|c|c|c|c|c|c|}
\hline \multirow{2}{*}{ Comp. } & \multicolumn{9}{|c|}{ Results for X } & \multicolumn{6}{|c|}{ Results for Y } \\
\cline { 2 - 16 } & M1 & M2 & M3 & M4 & M5 & M6 & M1 & M2 & M3 & M4 & M5 & M6 \\
\hline $\mathbf{3 0}$ & 39.79 & 29.77 & 32.54 & 25.19 & 22.10 & 23.83 & 0.79 & 0.78 & 0.54 & 0.45 & 0.38 & 0.42 \\
\hline $\mathbf{4 0}$ & 38.57 & 27.54 & 30.05 & 21.25 & 16.84 & 19.57 & 0.80 & 0.77 & 0.49 & 0.38 & 0.29 & 0.35 \\
\hline $\mathbf{5 0}$ & 37.79 & 25.42 & 27.65 & 18.38 & 12.98 & 16.57 & 0.81 & 0.76 & 0.45 & 0.33 & 0.23 & 0.30 \\
\hline $\mathbf{6 0}$ & 37.30 & 23.62 & 25.73 & 16.04 & 10.26 & 14.58 & 0.82 & 0.76 & 0.42 & 0.30 & 0.18 & 0.27 \\
\hline $\mathbf{7 0}$ & 36.92 & 22.10 & 23.95 & 14.47 & 8.69 & 12.94 & 0.82 & 0.76 & 0.39 & 0.27 & 0.16 & 0.25 \\
\hline $\mathbf{8 0}$ & 36.66 & 20.73 & 22.59 & 13.14 & 7.64 & 11.88 & 0.82 & 0.76 & 0.37 & 0.25 & 0.14 & 0.23 \\
\hline $\mathbf{9 0}$ & 36.52 & 19.30 & 21.49 & 12.11 & 6.81 & 10.94 & 0.82 & 0.76 & 0.35 & 0.23 & 0.12 & 0.22 \\
\hline $\mathbf{1 0 0}$ & 36.36 & 18.24 & 20.64 & 11.33 & 6.31 & 10.11 & 0.82 & 0.76 & 0.33 & 0.22 & 0.12 & 0.21 \\
\hline $\mathbf{1 1 0}$ & 36.29 & 17.05 & 19.76 & 10.49 & & 9.41 & 0.83 & 0.76 & 0.32 & 0.21 & 0.11 & 0.20 \\
\hline $\mathbf{1 2 0}$ & 36.19 & 16.08 & 18.99 & 9.97 & & & 0.83 & 0.76 & 0.31 & 0.20 & 0.11 & 0.19 \\
\hline $\mathbf{1 3 0}$ & 36.11 & 15.23 & 18.48 & 9.35 & & & 0.83 & 0.76 & 0.30 & 0.19 & 0.10 & \\
\hline
\end{tabular}

Table 3: MAPE values for each of the generated models.

\begin{tabular}{|l|c|c|c|c|c|c|c|c|c|c|c|c|}
\hline \multirow{2}{*}{ Comp. } & \multicolumn{9}{|c|}{ Results for X } & \multicolumn{5}{|c|}{ Results for Y } \\
\cline { 2 - 13 } & M1 & M2 & M3 & M4 & M5 & M6 & M1 & M2 & M3 & M4 & M5 & M6 \\
\hline $\mathbf{3 0}$ & $51.1 \%$ & $28.1 \%$ & $43.2 \%$ & $23 \%$ & $29.2 \%$ & $21.5 \%$ & $42.9 \%$ & $41.5 \%$ & $28.5 \%$ & $20.5 \%$ & $19.4 \%$ & $19.0 \%$ \\
\hline $\mathbf{4 0}$ & $48.6 \%$ & $25.3 \%$ & $39.7 \%$ & $18.7 \%$ & $22.1 \%$ & $17.1 \%$ & $43.7 \%$ & $41.0 \%$ & $26.2 \%$ & $168 \%$ & $15 \%$ & $15.3 \%$ \\
\hline $\mathbf{5 0}$ & $47 \%$ & $23.1 \%$ & $36.2 \%$ & $15.8 \%$ & $16.6 \%$ & $14.3 \%$ & $44.0 \%$ & $40.6 \%$ & $24.0 \%$ & $14.5 \%$ & $11.6 \%$ & $13.3 \%$ \\
\hline $\mathbf{6 0}$ & $45.9 \%$ & $21.2 \%$ & $33.5 \%$ & $13.6 \%$ & $12.8 \%$ & $12.5 \%$ & $44.2 \%$ & $40.3 \%$ & $22.3 \%$ & $12.9 \%$ & $9.3 \%$ & $12.1 \%$ \\
\hline $\mathbf{7 0}$ & $45.3 \%$ & $19.8 \%$ & $31.3 \%$ & $12.2 \%$ & $10.7 \%$ & $11.1 \%$ & $44.4 \%$ & $40.2 \%$ & $20.9 \%$ & $11.9 \%$ & $8.0 \%$ & $11.1 \%$ \\
\hline $\mathbf{8 0}$ & $44.8 \%$ & $18.4 \%$ & $29.4 \%$ & $11 \%$ & $9.3 \%$ & $10.2 \%$ & $44.5 \%$ & $40.2 \%$ & $19.7 \%$ & $11 \%$ & $7.2 \%$ & $10.4 \%$ \\
\hline $\mathbf{9 0}$ & $44.5 \%$ & $17.1 \%$ & $27.8 \%$ & $10.1 \%$ & $8.0 \%$ & $9.4 \%$ & $44.5 \%$ & $40.1 \%$ & $18.7 \%$ & $10.2 \%$ & $6.5 \%$ & $9.8 \%$ \\
\hline $\mathbf{1 0 0}$ & $44.3 \%$ & $16.1 \%$ & $26.6 \%$ & $9.4 \%$ & $7.3 \%$ & $8.7 \%$ & $44.5 \%$ & $40.1 \%$ & $17.9 \%$ & $9.7 \%$ & $6.1 \%$ & $9.3 \%$ \\
\hline $\mathbf{1 1 0}$ & $44.2 \%$ & $15 \%$ & $25.5 \%$ & $8.7 \%$ & & $8.1 \%$ & $44.5 \%$ & $40.1 \%$ & $17.2 \%$ & $9.2 \%$ & $5.8 \%$ & $8.9 \%$ \\
\hline $\mathbf{1 2 0}$ & $44 \%$ & $14.1 \%$ & $24.4 \%$ & $8.2 \%$ & & & $44.5 \%$ & $40.1 \%$ & $16.4 \%$ & $8.8 \%$ & $5.6 \%$ & $8.5 \%$ \\
\hline $\mathbf{1 3 0}$ & $43.9 \%$ & $13.3 \%$ & $23.8 \%$ & $7.7 \%$ & & & $44.5 \%$ & $40.1 \%$ & $16.0 \%$ & $8.4 \%$ & $5.4 \%$ & \\
\hline
\end{tabular}


observed that they are very similar to those obtained by the M4 model, which indicates that the inclusion of the maximum wave height has hardly any influence on the model.

Therefore, the M5 model with a complexity of 80 is selected as the optimal model. With this complexity, admissible errors of $7.5 \mathrm{~m}$ in the distance to the coast and $14 \mathrm{~cm}$ in the depth are reached, which corresponds to a MAPE of 9.3\% and 7.2\%, respectively. If this model is compared with the results obtained using the formulations or models proposed by other authors (see Section 3.2), it can be seen (Table 4) that the model generated (M5) considerably improves these results. If one analyses the formulations that use the same variables (S\&H and G\&K) for the coast distance, the model reduces the absolute error by $56.6 \mathrm{~m}$ and $53.8 \mathrm{~m}$ respectively, while for depth the error decreases in the order of $90 \mathrm{~cm}$. The smallest reduction in error occurs when comparing the M5 model with the ANN, and yet the reduction is $16 \mathrm{~m}$ in the distance to the coast and $29 \mathrm{~cm}$ in depth.

Table 4: Comparison of errors between the model generated (M5) and the formulations proposed by other authors.

\begin{tabular}{|c|c|c|c|c|c|c|}
\hline Models & M5 & $\mathbf{H}$ & S\&H & G\&K & $\mathbf{K}$ & ANN \\
\hline $\begin{array}{l}\text { Number of } \\
\text { variables }\end{array}$ & 3 & 4 & 3 & 3 & 4 & 7 \\
\hline Variables & $\begin{array}{l}\mathrm{H}_{\mathrm{s}, 12}, \mathrm{~T} \\
\text { and } \mathrm{D}_{50}\end{array}$ & $\begin{array}{l}\mathrm{H}_{\mathrm{s}, 12}, \mathrm{~T} \\
\Theta \text { and } \mathrm{m}\end{array}$ & $\begin{array}{l}\mathrm{H}_{\mathrm{s}, 12, \mathrm{~T}} \\
\text { and } \mathrm{m}\end{array}$ & $\begin{array}{l}\mathrm{H}_{\mathrm{s}, 12, \mathrm{~T}} \\
\text { and } \mathrm{m}\end{array}$ & $\begin{array}{l}\mathrm{H}_{\mathrm{s}, 12}, \mathrm{~T}, \\
\mathrm{~m} \text { and } \\
\mathrm{D}_{50}\end{array}$ & $\begin{array}{l}\text { Month, } \mathrm{H}_{\max } / \mathrm{L}_{\text {omax }}, \\
\text { Ohmax, Days, } \mathrm{H}_{\mathrm{m}}, \mathrm{D}_{50}, \\
\text { Beach width difference } \\
\text { between profiles }\end{array}$ \\
\hline$R^{2}$ for $X$ & 0.940 & 0.229 & 0.179 & 0.179 & 0.000 & 0.706 \\
\hline$R^{2}$ for $Y$ & 0.937 & 0.105 & 0.004 & 0.004 & 0.059 & 0.621 \\
\hline Absolute error X & 7.6 & 315.3 & 64.2 & 53.8 & 203.7 & 23.6 \\
\hline Absolute error Y & 0.138 & 1.20 & 1.05 & 1.04 & 1.01 & 0.42 \\
\hline MAPE in $\mathrm{X}$ & $9.3 \%$ & $289.2 \%$ & $61.1 \%$ & $47.0 \%$ & $270.5 \%$ & $28.5 \%$ \\
\hline MAPE in Y & $7.2 \%$ & $48.2 \%$ & $47.1 \%$ & $49.3 \%$ & $42.8 \%$ & $23.3 \%$ \\
\hline
\end{tabular}

\section{DISCUSSION}

Correct determination of the location of sand bars has important implications for coastal engineering. Therefore, if we are able to determine the exact position or range of motion of the bars, we will be able to determine with greater precision the influential elements in the calculation of the coastal protection elements or the volumes of sand needed for a nourishment. For this reason, this article has attempted to optimize existing formulations and models for the determination of the bar crest. Thus, different numerical models based on Galerkin's formulation [15] have been generated using different input variables. The use of Galerkin's formulation of the finite element method and the corresponding improvement in computational efficiency allows us to analyse relationships in which a greater number of variables are involved without this implying a high time in the execution of the software.

Comparing the results obtained using numerical models with existing formulations shows that there is a big difference. As for $\mathrm{R}^{2}$, the proposed formulations do not have a good fit in the study area with values lower than 0.25 , while the neural network proposed for the study area reaches values of 0.7 . With the generated numerical model (M5), which has three variables and a complexity of 80 , values of $\mathrm{R}^{2}$ greater than 0.93 are reached. This difference in the adjustment is also observed in the errors. Thus, the numerical model selected results in an absolute error about three times lower than that of the ANN proposed by López et al. [26], 
which is the one that results in the least error of the different models proposed by other authors (Table 6).

Given that the selected model has been generated using variables proposed and used by other authors [22]-[26], and the errors obtained are much smaller, it can be deduced that the influential variables in the bars are the same in any area of study, but the degree of influence or relationship with the study parameter depend on the study area. Therefore, it is necessary to generate different models depending on the characteristics of the study area or, in order to be able to use a model globally, it would be necessary to generate a single model that includes (in its generation) data from all over the world.

Finally, the proposed new model associated with other similar tools such as the determination of erosion [27] or bar volume [28], becomes not only a tool for bar knowledge, but also an additional method for coastal control and management, which may imply a reduction in both construction and maintenance costs.

\section{CONCLUSION}

In this paper a numerical model based on Galerkin's formulation of the finite element method has been developed, which allows to reduce the computation time and to generate families of numerical models with high complexity. Among the different models generated it can be stated that:

- The use of three variables $\left(\mathrm{H}_{\mathrm{s}, 12}, \mathrm{~T}\right.$ and $\left.\mathrm{D}_{50}\right)$ is enough to generate models with high precision in the determination of the sand bar. It achieves errors of less than $10 \%$ for the distance to the coast and $7.5 \%$ for the depth of the bar crest.

- The use of the median sediment size $\left(\mathrm{D}_{50}\right)$ influences the improvement of the model results much more than the inclusion of the profile slope.

- The influential variables in the bars are the same in any study area, but the degree of influence or relationship with the study parameter depend on the study area.

\section{ACKNOWLEDGEMENT}

This work was partially supported by the Universidad de Alicante through the project "Estudio sobre el desgaste y composición de los sedimentos y su influencia en la erosión de las playas españolas" (GRE16-09).

\section{REFERENCES}

[1] Holman, R.A. \& Sallenger Jr, A.H., Sand Bar Generation: A Discussion of the Duck Experiment Series. Journal of Coastal Research, pp. 76-92, 1993.

[2] Takeda, I. \& Sunamura, T., Beach changes by storm waves. Coastal Engineering Proceedings, 1(20), 1986.

[3] Seymour, R.J., An assessment of NSTS, Coastal Sediments (1987), ASCE, pp. 642651, 1987.

[4] Dyhr-Nielsen, M. \& Sorensen, T., Some sand transport phenomena on coasts with bars. Proceedings of the 12th Coastal Engineering Conference, American Society of Civil Engineers, pp. 855-865, 1971.

[5] Holman, R.A. \& Bowen, A.J., Bars, bumps, and holes: Models for the generation of complex beach topography. Journal of Geophysical Research: Oceans, 87(C1), pp. 45-68, 1982.

[6] Trowbridge, J. \& Young, D., Sand transport by unbroken water waves under sheet flow conditions. Journal of Geophysical Research: Oceans (1978-2012), 94(C8), pp. 10971-10991, 1989. 
[7] Gallagher, E.L., Elgar, S. \& Guza, R., Observations of sand bar evolution on a natural beach. Journal of Geophysical Research: Oceans, 103, pp. 3203-3215, 1998.

[8] Plant, N., Holman, R. Freilich, M. \& Birkemeier, W., A simple model for interannual sandbar behavior. Journal of Geophysical Research: Oceans (1978-2012), 104(C7), pp. 15755-15776, 1999.

[9] Pape, L., Ruessink, B.G., Wiering, M.A. \& Turner, I.L., Recurrent neural network modeling of nearshore sandbar behavior. Neural Networks, 20(4), pp. 509-518, 2007.

[10] Różyński, G., Data-driven modeling of multiple longshore bars and their interactions. Coastal Engineering, 48(3), pp. 151-170, 2003.

[11] Masselink, G. \& Short, A.D., The effect of tide range on beach morphodynamics and morphology: a conceptual beach model. Journal of Coastal Research, pp. 785-800, 1993.

[12] ECOLEVANTE, Estudio ecocartográfico de las provincias de Valencia y Alicante, in: D.G.d. Costas (ed.) Ministerio de Medio Ambiente, 2006.

[13] Serra, J. \& Medina, J.R., Beach monitoring program of Valencia (Spain). Proceedings of the 25th Coastal Engineering, pp. 590-591, 1996.

[14] IHCantabria, Análisis Matemático y Estadístico de Variables Medioambientales (AMEVA), in: U.d. Cantabria (ed.) Cantabria, Spain. Available online: http://ihameva.ihcantabria.com/, 2013.

[15] Navarro-González, F.J. \& Villacampa, Y., A finite element numerical algorithm for modelling and data fitting in complex systems. International Journal of Computational Methods and Experimental Measurements, 4(1), pp. 100-113, 2016.

[16] Zienkiewicz, O.C., Taylor, R.L. \& Zhu, J.Z., The finite element method: its basis and fundamentals, Elsevier Butterworth-Heinemann, 2005.

[17] Hatami, M., Weighted Residual Methods, Academic Press, 2018.

[18] Navarro-González, F.J. \& Villacampa, Y., A new methodology for complex systems using n-dimensional finite elements. Advances in Engineering Software, 48(1), pp. 52$57,2012$.

[19] Aragonés, L., Villacampa, Y., Navarro-González, F.J. \& López, I., Numerical modelling of the equilibrium profile in Valencia (Spain). Ocean Engineering, 123, pp. 164-173, 2016.

[20] Aragonés, L., López, I., Villacampa, Y. \& Navarro-González, F.J., Using the presence of seagrass Posidonia oceanica to model the equilibrium profile parameter A of sandy beaches in Spain. Journal of Coastal Research, 33(3), pp. 642-652, 2017.

[21] Navarro-González, F.J. \& Villacampa, Y., Generation of representation models for complex systems using Lagrangian functions. Advances in Engineering Software, 64, pp. 33-37, 2013.

[22] Hsu, T.-W., Geometric characteristics of storm-beach profiles caused by inclined waves. Ocean Engineering, 25(1), pp. 69-84, 1998.

[23] Silvester, R. \& Hsu, J.R., Coastal stabilization. Advanced Series on Ocean Engineering, p. 14, 1997.

[24] Günaydın, K. \& Kabdaşlı, M.S., Investigation of offshore bar geometry under regular and irregular waves. Journal of Coastal Research, pp. 374-382, 2005.

[25] Kömürcü, M., Özölçer, İ., Yüksek, Ö. \& Karasu, S., Determination of bar parameters caused by cross-shore sediment movement. Ocean Engineering, 34(5), pp. 685-695, 2007.

[26] López, I., Aragonés, L., Villacampa, Y. \& Serra, J.C., Neural network for determining the characteristic points of the bars. Ocean Engineering, 136, pp. 141-151, 2017. 
[27] Tsekouras, G.E., Rigos, A., Chatzipavlis, A. \& Velegrakis, A., A Neural-Fuzzy Network Based on Hermite Polynomials to Predict the Coastal Erosion, in: L. Iliadis, C. Jayne (eds), Engineering Applications of Neural Networks: 16th International Conference, EANN 2015, Rhodes, Greece, pp. 195-205, 2015.

[28] Demirci, M., Üneş, F. \& Aköz, M.S., Prediction of cross-shore sandbar volumes using neural network approach. Journal of Marine Science and Technology, 20(1), pp. 171179, 2015. 